\title{
Design and Application of SCORM-Based Distance Education Management System
}

\author{
http://dx.doi.org/10.3991/ijet.v10i2.4482 \\ Hui Cai ${ }^{*}$, Kanhua Yu \\ Chang'an University, Xi'an, China
}

\begin{abstract}
Demand for civil engineering talents continues to grow with the popularity of network and the constant development of the Chinese economy. However, current demands cannot be met because of shortage in relevant teaching resources in universities and colleges. In this situation, distance network education becomes a popular approach for off-campus personnel to further their studies. Shareable content object reference model (SCORM) standards are widely used in the distance education system in the international arena. The model has become a wind indicator within the industry because of its efficient handling of problems related to cross-platform resource transfer. This research succeeds in developing a SCORM-based education management system targeted toward all civil engineering learners and features independent learning, track record, and information feedback.
\end{abstract}

Index Terms-SCORM, distance education, platform design, civil engineering

\section{INTRODUCTION}

Shareable content object reference model (SCORM)based distance education management system is a distance teaching model system. SCORM refers to a series of unified standards formulated after the integration of multiple learning standards. SCORM standards constitute a set of widely recognized network technique education standards in the international arena [1]. In recent years, China has faced an increasing demand for civil engineering talents, but the limited teaching resources in domestic universities and colleges have failed to satisfy such a demand. Distance network education becomes especially important under the circumstances. In view of the popularity of the Internet and the increasing demands for further study, Internet-based distance education model has gained increasing acceptability and gradually became a new teaching method. Network education is open, shareable, and unrestricted by time and space; thus, it can provide an independent optional learning environment whenever and wherever for learners [2]. SCORM-based distance education management system is established based on SCORM standards. Under the management system, any courseware, video, and teaching material can be used and operated repeatedly on different platforms. Learning plans and records can also be tracked. All these characteristics can better satisfy learners' demands.

Victor reviews and compares SCORM and Common Cartridge from an educational perspective, Suggestions are made to education practitioners on learning objects standards adoption in the most common scenarios [3]. Researchers have extended SCORM by adding semantic annotations of the textual fields with respect to ontologies modeling the course contents. They also describe a Semantic Web application capable of importing SCORM courses, and supporting their semantic annotation and the semantic retrieval of contents [4].

SCORM started late in China and focused mainly on translation, introduction of SCORM standard specifications, and development of learning management system based on SCORM standards [5, 6]. Thus, scholars are concerned with development of SCORM standards in courses. For instance, Cao Wei [7] applied SCORM standards to the research and design of web-based learning resource management system. However, such an application is confined to creating courseware, and SCORM standards are not completely expanded to the construction of web-based courses. Thus, design methods of web-based courses based on SCORM standards should be studied further to accumulate experience. In this study, SCORM is used to solve problems in distance education management system for civil engineering education, such as poor reusability and sharing of web-based teaching materials, learning loss, and retention of learning traces. A standardized web-based teaching platform is thus realized. Analysis and evaluation of students' learning conditions can assist students or the system to arrange learning progress reasonably and provide reference for building web-based courses based on SCORM standards for other majors.

Comparison of three platform systems indicated that SCORM has the following advantages. First, in terms of techniques, SCORM supports sharing of learning content. It can formulate learning plans in line with learners' personal abilities, and it can track, record, and test learners' performance. Second, SCORM puts forth three important specifications, including course structure format (CSF), run time environment (RTE), and definition of Meta data. Any teaching material that fully meets the above three formats can transfer to different SCORM platforms. Third, SCORM provides standard method to define and save learners' information. As long as the data used meets the standard, different teaching systems on different platforms can be transferred by spanning programming language and script language obstacles. Therefore, the study and development of software related to SCORM-based distance education management system is of vital significance.

\section{DESIGN OF A SCORM-BASED CIVIL ENGINEERING Distance EduCATION MANAGEMENT SySTEM}

\section{A. SCORM standards and content}

SCORM standards were developed by the American institution Advanced Distributed Learning (ADL). The company formulated a series of standards, such as content reuse, content accessibility and durability, and collabora- 
tive and independent learning ability, to meet the demands for independent distance learning and achieve its business objectives. Its ultimate goal is to realize collaboration between various education or training institutions, built online education content, and relevant application markets that can help materialize modularized online education.

A major content of SCORM standards is the content aggregation model (CAM). SCORM CAM establishes a new package lecturing method that can combine various learning data automatically, define and describe such data, integrate them into a brand-new course or a part of a course, and solve problems related to the transfer of learning knowledge between knowledge bank and backstage management system. The latest SCORM 2004 CAM introduces the sequence control content, which can provide additional learning convenience compared with SCORM1.2. SCORM CAM also redefines the sequence navigation and meta data. Sequence handles mainly the learning activities, whereas LMS is responsible for the analysis and definition of the sequence information in content organization. SCORM CAM is composed mainly of the following parts:

(1) Content module: This part defines learning content modules of different levels of difficulty. Modules include asset, shareable content object (SCO), and CAM. Asset is the minimum component in the course learning content. SCO is a collection of SCOs, among which at least one asset should be bootable. The SCO can correspond based on SCORM-defined RTE and LMS. SCO is the minimum learning content unit that can be tracked by RTE. The composition of CAM resembles that of the content and can be used to arrange course content.

(2) Content package: This part is used to list the CAM. By referring to the content packaging standards of IMS, the shareable learning content can be arranged according to the content structure. Resources such as SCO, asset, and Meta data can be packaged into a package interchange file (PIF) in the document format of zip, jar, and cab to facilitate transfer of learning content. The packaged or arranged content can be a complete learning content or several knowledge points.

(3) Meta data: SCORM built its own metadata model by referring to some merits of LOM standards of IEEE LTSC and XML standards of IMS. SCORM meta data information modules are divided into nine categories of meta data information, with every category subdivided into many concrete sub-categories. In this way, the meta data can confirm the learners' demands precisely [8].

(4) Sequence and navigation: Sequence and navigation are used to achieve navigation and order arrangement of content, in line with SCORM. Some content can be described in advance or predefined during the sequence design. This part also describes how LMS in line with SCORM expounds the ordering rules according to the influence of learners and system on RTE. SCORM defines methods on how to sequence unified and fragmented shareable learning resources and navigate into relevant objects with an advanced structure.

\section{B. Management system design}

\section{1) MVC structure design}

Input, operation, and output are separated in the application program in accordance with the structure form from the model to the view to the MVC. These parts are then divided into three core components, namely, the model, view, and MVC. The three components operate independently without influencing each other. In LMS based on SCORM standards, learners see content as being composed of SCOs, and they can issue relevant orders through the navigation system. The program design features completed specialized course development tools.

The AdminActions.xml configuration codes of the MVC partial structure are shown below.

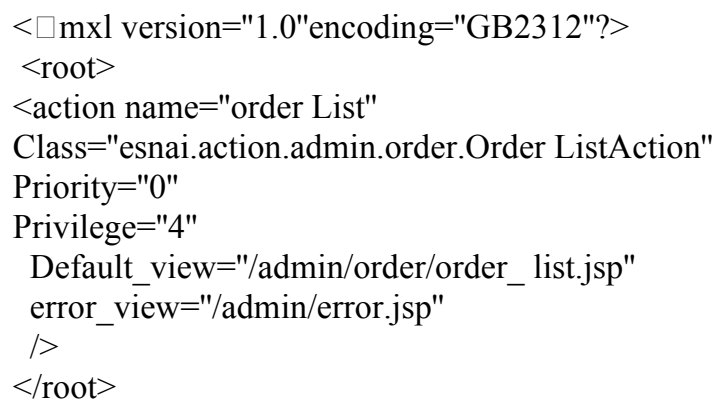

\section{2) AJAX framework design}

Asynchronous Java script and XML (AJAX) is an application method that integrates multiple techniques. The method uses XHTML and CSS standards to demonstrate, DOM to achieve dynamic display and interaction, XML and XSTL to conduct data exchange and processing, XMLH (i.e., namely request object) to conduct asynchronous data reading, and Javascript to bind and process all data. The distance education platform adopts the AJAX framework to achieve API adapter. This method is a great improvement compared with the ordinary methods in terms of browser's compatibility and can achieve the same favorable operation status in different operation systems and browsers. The AJAX framework adopts the asynchronous interaction and thus, all data are managed by the system in the backstage. This setup can enhance user experience because users do not need to refresh the page.

The data items of the AJAX structure SCORM data model are conveyed through JSON. The data element codes packaged by JSON are shown below.

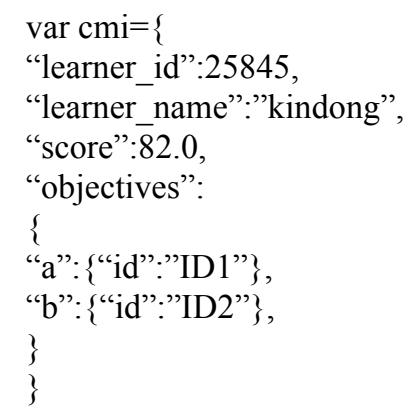

This research designs the structural model shown in Fig. 1 based on the above principles. The structure uses the AJAX and MVC structure designs comprehensively and combines the two. Modules of various layers independently handle customer visit information without disturbing each other. The structure conducts information transfer within the system through RTE and LMS based on CAM. Finally, the teaching information can be freely transferred between different platforms. 
PAPER

DESIGN AND APPLICATION OF SCORM-BASED DistANCE EdUCATION MANAGEMENT System

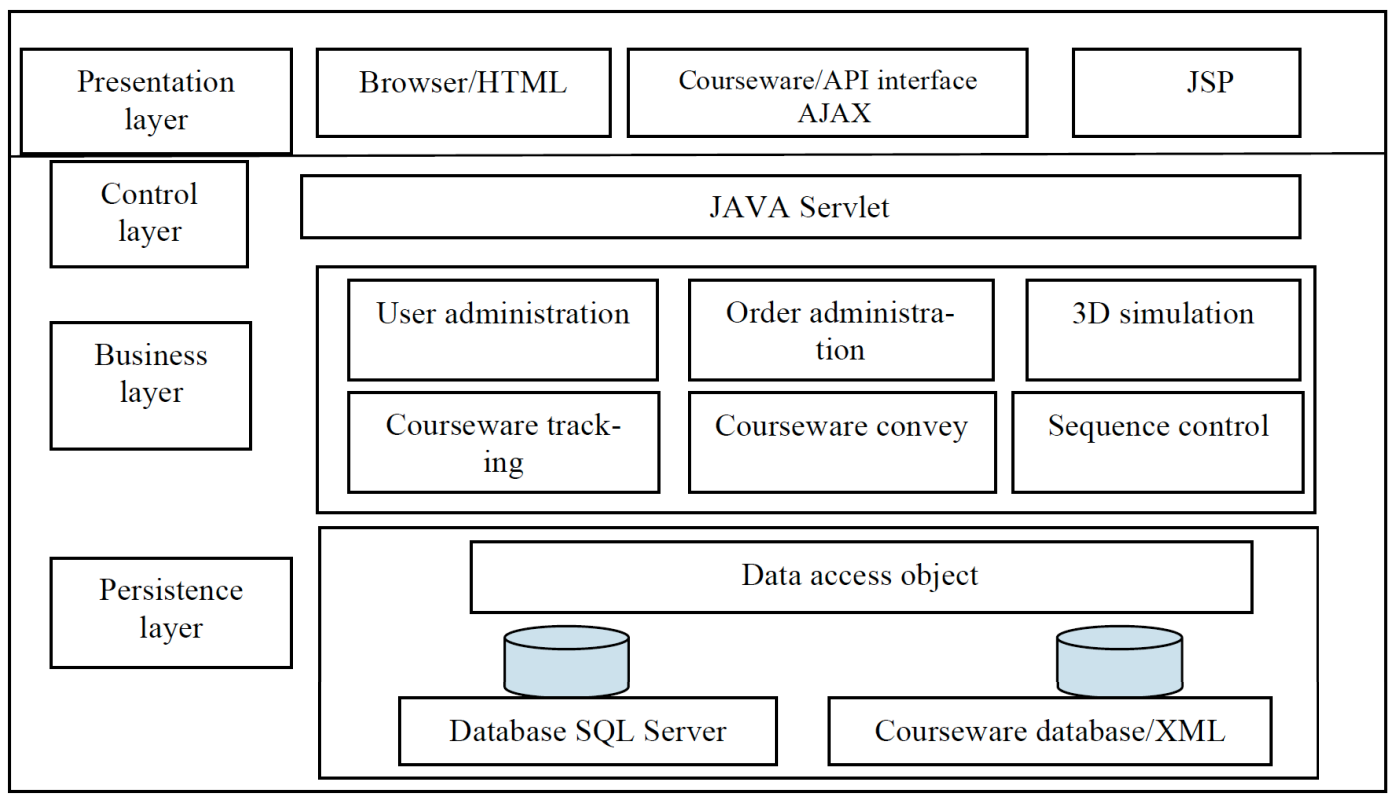

Figure 1. Distance education platform system structure chart

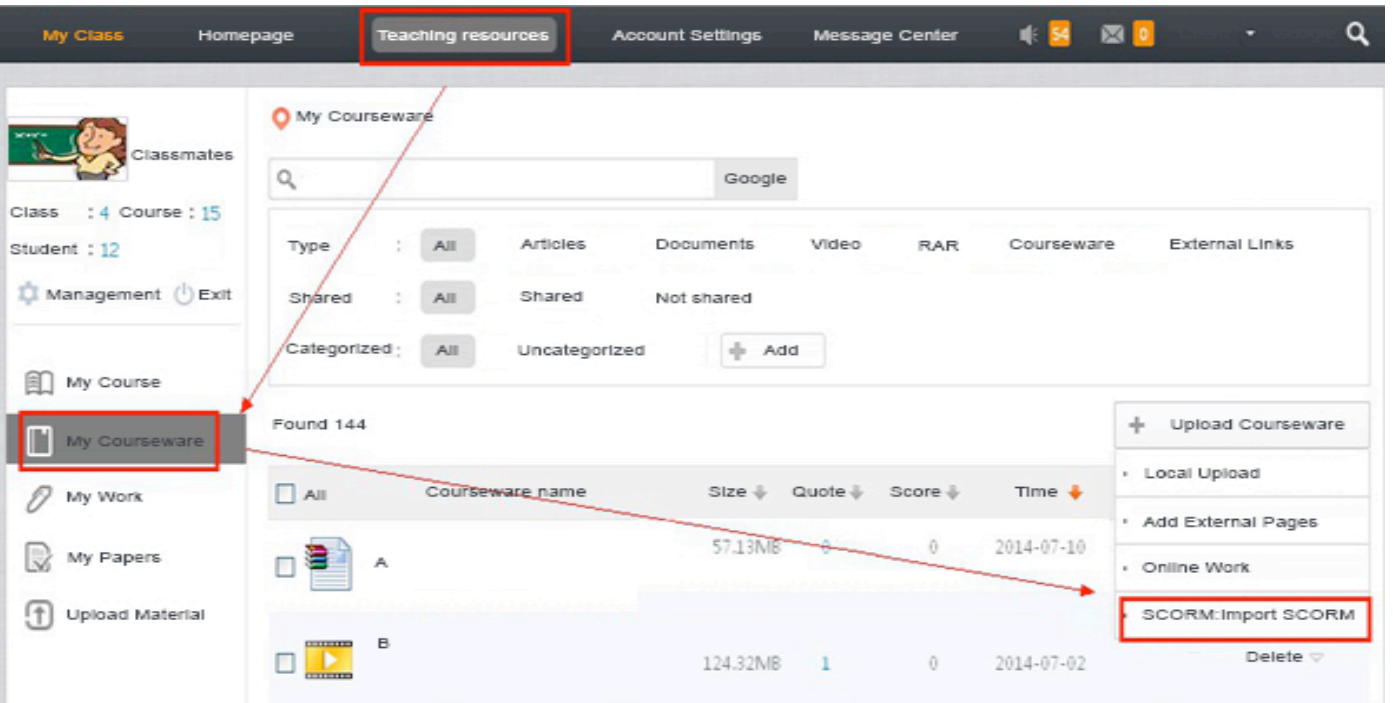

Figure 2. Interface of Civil Engineering major and distance education platform based on SCORM

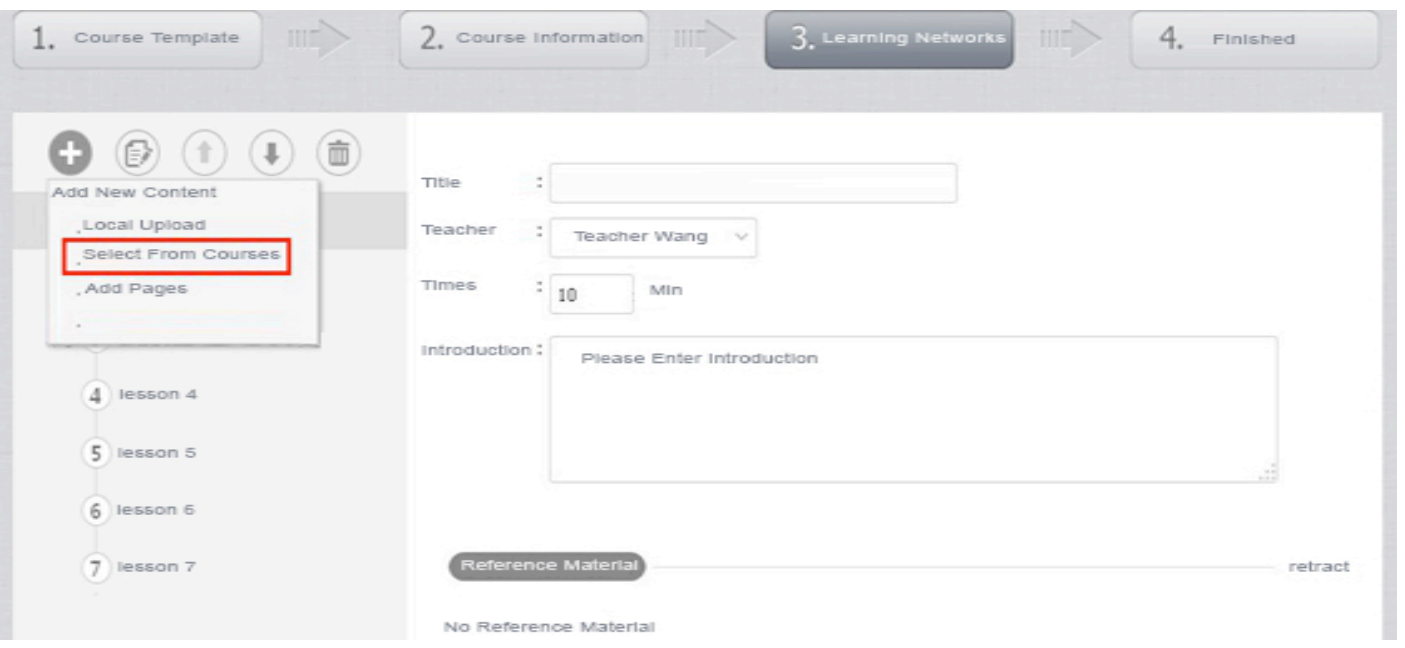

Figure 3. Interface of Civil Engineering major and distance education platform based on SCORM 


\section{3) Core sub-system design}

The construction of the distance education platform focuses mainly on the improvement of the current platform based on SCORM. The system design is based on SCORM standards to conduct reconstruction of major modules. User visit and tracking function are added according to the SCORM data model. Students not only master basic theories, but also gain practical experiences of civil engineering design, projects, and effect based on the teaching objective and teaching forms of civil engineering. In distance education, the major interaction is completed through question and answer (Q\&A), and thus, the system includes three parts, namely, simulated class sub-system, video sub-system, and Q\&A sub-system.

Simulated class sub-system: Courseware study refers mainly to the study of text format courseware. The text format courseware is issued to the content of a specific network through FTP. In a distance education platform, the system can use the courseware directly through the links.

The core sub-system design for civil engineering adopts the framework design model. The API adaptor is realized through hidden frames on the top level and used to correspond with the LMS server. The courseware navigation provides the recommended learning sequence, but the system also allows the learner to choose the learning content independently according to their own learning demands. After the SCO is loaded, the API adaptor can be found through the standard Javascript. After initialization, the API adaptor begins to correspond with LMS. When learners leave the page, the API adaptor can submit the record formatted data to LMS and save them in the database.

Video class sub-system: The video courseware features the standard three-frame model. Video courseware learning calls for sound network speed. The compressed code rate of the teaching video should also be set at a proper value. The SCORM system can record learners' video courseware learning situation and turn to the relevant time node directly to record the last time.

Most importantly, the system can introduce the numerical modeling simulation test to classroom teaching on the platform. The simulation technique can conduct material, component, and structure multi-layer test numerical modeling simulation using powerful modeling, animation display, and data output function. As students learn theoretical knowledge, the vivid 3D design can enhance their understanding of bending failure mechanism, such as loading features, deformation performance, and crack developing rules of various structures and interfaces in terms of civil engineering.
Q\&A center sub-system: The introduction of SCORM standards can solve the problems of failure to track learners and help learners raise questions. All data interfaces are designed with a "Q\&A" button, and the API adaptor can be used to record the current learning content. The AJAX technique can assist learners in raising questions at any time during the study process. Learners' questions and accurate courseware positioning (such as knowledge points included in the civil engineering text format courseware and certain time node of engineering videos) can help teachers obtain learning feedback even if learners may have difficulty expressing them.

Compared with the traditional distance education platform, the proposed platform holds the advantage of a simulation software adapted to civil engineering, thereby enabling student learning outcomes to improve significantly. The system also features Q\&A as part of the teacher-student interaction, it also tracks and records progress so the students that will enable students to determine what their learning deficiencies are upon their review.

\section{APPLICATION OF SCORM-BASED CIVIL}

\section{ENGINEERING DisTANCE EDUCATION MANAGEMENT} SYSTEM

\section{A. Experimental objects}

A total of 160 civil engineering students (85 males and 75 females) of a university were randomly chosen as research objects. Classes 1-4 consisting of 80 students were regarded as the experimental group and Class 5-8 with 80 students were regarded as the control group. The experimental group studied on the SCORM-based education platform, whereas the control group studied on the traditional education platform. The knowledge learned by the two groups and the learning time were similar, that is, one semester or 56 credit hours.

\section{B. Learning result evaluation methods}

At the end of every semester, each student participating in the experiment was evaluated according to the above three indices. The overall experimental results are shown in Table 1.

Table 1 shows that the SCORM-based new distance education platform can help civil engineering students significantly improve their learning efficiency. Although only a small difference could be observed in the cognitive competence of the students, the new education system is significantly better than the traditional one.

The test results of civil engineering students in every subject shown in Table 2 indicate that the basic knowled-

TABLE I

COMPARISON OF THE OVERALL EXPERIMENTAL RESULTS

\begin{tabular}{ccccc}
\hline Group & Index 1 & Index 2 & Index 3 & Comprehensive scores \\
\hline Control group & 69.62 & 67.34 & 56.83 & 61.06 \\
Experimental group & 87.56 & 76.23 & 68.71 & 70.21 \\
\hline
\end{tabular}

TABLE II.

RESULTS OF THE TESTS ON THE BASIC KNOWLEDGE OF CIVIL ENGINEERING STUDENTS

\begin{tabular}{|c|c|c|c|c|c|}
\hline Group & $\begin{array}{c}\text { Civil Engineering } \\
\text { Materials }\end{array}$ & $\begin{array}{c}\text { Concrete Structure } \\
\text { Design }\end{array}$ & $\begin{array}{c}\text { Steel Structure } \\
\text { Design }\end{array}$ & $\begin{array}{c}\text { Pre-stressed Concrete Struc- } \\
\text { ture Design }\end{array}$ & $\begin{array}{l}\text { Average } \\
\text { scores }\end{array}$ \\
\hline Control group & 78 & 72 & 69 & 67 & 67.5 \\
\hline Experimental group & 85 & 83 & 66 & 83 & 75.25 \\
\hline
\end{tabular}


ge of students on the SCORM-based network education platform is more complete than that on the traditional platform. Relying on the free transfer of data between different platforms, learners can obtain the necessary knowledge at a relaxed pace, and thus, their test scores are a little higher than those of leaners on the ordinary network education platform.

\section{CONCLUSIONS}

This paper expounds on a SOCRM-based distance education platform for civil engineering students from the perspective of system development and tests its application effect. The platform structure is flexible and features a course operation environment geared to international standards. The system also contains its own operational characteristics and meets the requirements of standardization. The platform has the following advantages:

All professional knowledge and data on the SCORMbased distance education platform conform to international standards, and all data can be transferred between different major platforms. The self-developed software is also applicable to domestic mainstream education institutions. Courseware transmission is likewise efficient and convenient.

The SCORM-based distance education management platform can track the entire learning process and achieve information exchange and automatic interaction. Information exchange between SCO and LMS can analyze and evaluate the learning situation of each learner and help them or the system to arrange the learning schedule properly.

\section{REFERENCES}

[1] S. Peng, "Learning Path Design Based on the SCORM Standards," Modern Education, no. 8, pp.114-119, August 2010
[2] P. Shen, "Study and Realization of the Network Education Platform Based on the SCORM2004 Standards," Shanghai: Shanghai Jiaotong University, 2005.

[3] G.B. Victor, "Luis Anido-Rifon $\square$ From SCORM to Common Cartridge: A step forward," Computers \& Education, vol.54, no. 1, pp.88-102, January 2010, http://dx.doi.org/10.1016/j.compedu.2009.07.009

[4] A. Esteban-Gil, J.T. Fernández-Breis, D. Castellanos-Nieves, "Semantic enrichment of SCORM metadata for efficient management of educative contents," Procedia Social and Behavioral Sciences, vol. 1, pp.927-932, December 2009. http://dx.doi.org/10.1016/j.sbspro.2009.01.164

[5] W. Cao, "Enterprise Network Learning Resources Management Model Based on SCORM Standards," Science \& Technology Progress and Policy, vol. 27, no.18, pp.83-85, September 2010.

[6] L. Ge, "Research and Implementation of Enterprise-level SCORM-based Learning Management Model," Journal of Xi'an Dianzi Keji University, vol. 23, no. 5, pp.122-126, May 2007.

[7] W. Cao, "Research on Management System of Standardized Learning Resource Oriented Smart Campus," Modern Computer, vol. 21, no.3, pp. 92-94, March 2013.

[8] F. Shi, "Network Distance Education Platform Based on SCORM Standards," Journal of Harbin University of Science and Technology, vol. 12, no. 3, pp.77-79, March 2007.

\section{AUTHORS}

Hui Cai (Corresponding author) is an associate professor in School of Architecture, Chang'an University, Xi'an, 710061, China. His research interests include urban architecture and distance education (caihui1@yeah.net)

Kanhua $\mathbf{Y u}$ is an associate professor in School of Architecture, Chang'an University, Xi'an, 710061, China. His research interests include urban architecture and distance education (yukanhua@yeah.net)

Submitted 19 February 2015. Published as resubmitted by the authors 24 March 2015. 